\title{
OPEN ACCESS TO SCIENTIFIC RESULTS AND DATA. EUROPEAN UNION'S EFFORTS THROUGH OPENAIRE AND OPENAIREPLUS FP7 PROJECTS: CYPRIOT PARTICIPATION
}

\author{
F.Ch. Tsimpoglou a, V.V. Koukounidou* a, L.A. Prokopiou a \\ a University of Cyprus Library, 75 Kallipoleos Str. P.O. Box 205371678 Nicosia, Cyprus \\ (tsimpoglou.filippos, sylviek, prokopiou.louis)@ucy.ac.cy
}

\begin{abstract}
KEY WORDS: Open access, OpenAIRE, OpenAIREplus, Scientific results, Data, EU, Seventh $\left(7^{\text {th }}\right)$ Framework Programme, European projects, Repositories, Cultural Heritage, Europeana, Public Sector Information (PSI) directive, Orphan works directive, European Commision
\end{abstract}

\begin{abstract}
:
The paper presents the introduction of Open Access movement in the Academic environment,pros and cons of the adoption of OA by Universities and how the European Union is enforcing the use of Open Access. The ways of implementing OA, the policies of publishers and journals regarding the deposits of publications and the RoMEO and Juliet projects are also referred in an effort to give an overview of the conditions in exploiting Open Access, either as authors, publishers or end users. The adoption of the Berlin declaration on Open Access to Knowledge in the Sciences and Humanities by the Senate of the University of Cyprus is commented in the paper. Furthermore an analysis of the projects OpenAIRE and OpenAIREplus in which the University of Cyprus Library is involved is provided.
\end{abstract}

\section{OPEN ACCESS}

\subsection{The way to Open Access - a short overview}

The pricing of journals over the last few decades has been leading to a decline in the availability of academic research results. Academia reached the level where even the affluent research institutions cannot afford access to the full range of research literature (Suber). Enforcing this statement we can see the recent movement of the Harvard Faculty Advisory Council to the Library, representing university faculty in all schools and in consultation with the Harvard Library leadership on the $17^{\text {th }}$ of April 2012, reaching the following conclusion: "major periodical subscriptions, especially to electronic journals published by historically key providers, cannot be sustained: continuing these subscriptions on their current footing is financially untenable. Doing so would seriously erode collection efforts in many other areas, already compromised". The announcement closes with the encouragement to the faculty and students (F) and the Library (L) as follows:

\begin{abstract}
- Make sure that all of your own papers are accessible by submitting them to DASH in accordance with the facultyinitiated open-access policies $(\mathrm{F})$.
\end{abstract}

- Consider submitting articles to open-access journals, or to ones that have reasonable, sustainable subscription costs; move prestige to open access (F).

- If on the editorial board of a journal involved, determine if it can be published as open access material, or independently from publishers that practice pricing described above. If not, consider resigning $(\mathrm{F})$.

- Contact professional organizations to raise these issues (F).

- Encourage professional associations to take control of scholarly literature in their field or shift the management of their e-journals to library-friendly organizations (F).

- Encourage colleagues to consider and to discuss these or other options (F).

- Sign contracts that unbundle subscriptions and concentrate on higher-use journals (L).

- Move journals to a sustainable pay per use system, (L).

- Insist on subscription contracts in which the terms can be made public (L).

This is a movement we can see been followed by many institutions that cannot afford or just disagree with the policies and prices of the journal providers.

\subsection{Defining Open Access}

European Commission defines "Open access", as free access over the internet, which aims to improve and promote the dissemination of knowledge, thereby improving the efficiency of scientific discovery and maximising return on investment in R\&D by public research funding bodies**.

Peter Suber defines open access as the digital, online, free of charge, and free of most copyright and licensing restrictions method of having access to scientific topics. What makes it possible is the internet and the consent of the author or copyright-holder (Suber).

OA was physically and economically impossible in the age of print, even if the copyright holder wanted it. Prices were not only unavoidable for print journals; they were even affordable until the 1970's, when they began to rise faster than inflation.

\footnotetext{
European commission - European research area open access pilot in FP7 http://ec.europa.eu/research/science-society/open_access
} 
Journal subscription prices have risen nearly four times faster than inflation since 1986 (Kyrillidou, 2004).

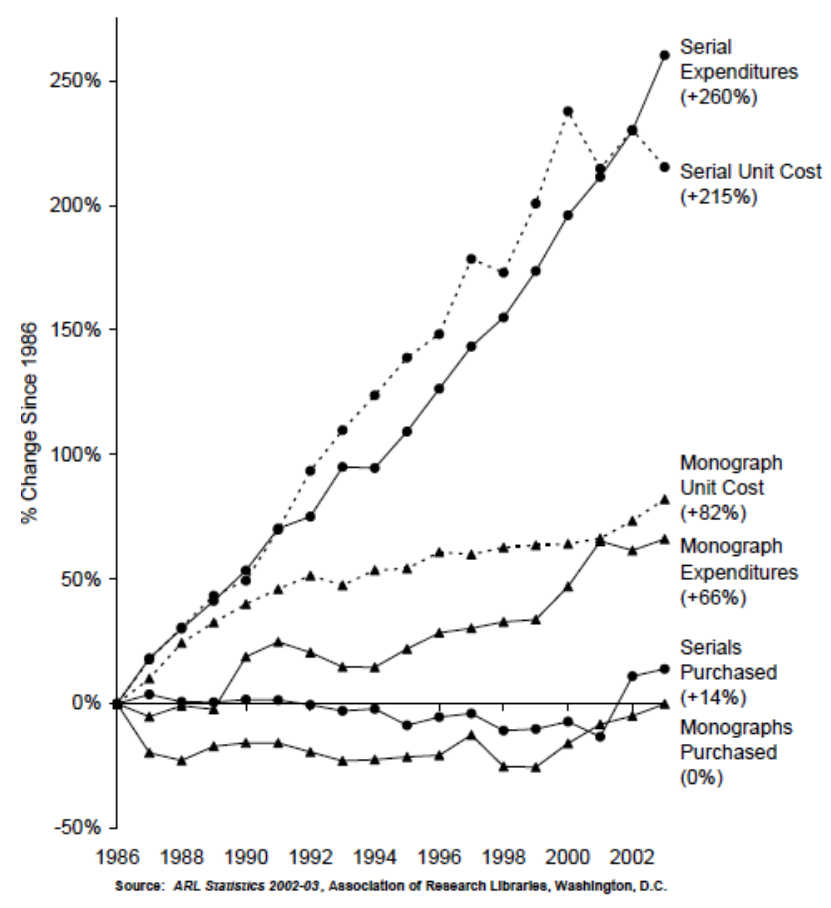

Figure 1. Monograph and serial costs in ARL Libraries, 1986 2003 (Kyrillidou, 2004)

Fortuitously, just as journal prices were becoming unbearable, the internet emerged to offer an alternative (Suber). This alternative was named Open access

\subsection{Publisher and journal policies}

Open access can be provided in two ways:

The Green route where the author can self-archive at the time of submission of the publication, whether the publication is grey literature (usually internal non-peer-reviewed), a peerreviewed journal publication, a peer-reviewed conference proceedings paper or a monograph and the Gold route where the author or author institution can pay a fee to the publisher at publication time and the publisher thereafter will make the material available 'free' at the point of access.

The two are not, of course, incompatible and can co-exist (Jeffery, 2006).

Publishers provide specific policies regarding how authors can deposit their own publications. These policies are concentrated and can be found in RoMEO $^{\dagger}$ (a searchable database of publisher's policies regarding the self- archiving of journal articles on the web and in Open Access repositories).

Researchers or academic community can use RoMEO to find out whether the publishers' copyright rules allow them to deposit in their institutional repository. It summarizes publishers' conditions and categorizes publishers by colours,

\footnotetext{
***The RoMEO Project (Rights MEtadata for Open archiving) was funded by the Joint Information Systems Committee for one year (1 August 2002 - 31 July 2003) to investigate the rights issues surrounding the 'self-archiving' of research in the UK academic community under the Open Archive Initiative's Protocol for Metadata Harvesting.
}

indicating level of author rights. Finaly RoMEO shows which publishers' comply with funding agencies' conditions.

As a way to complement RoMEO service SHERPA provides JULIET which lists summaries of publishers' copyright transfer agreements as they relate to archiving. Further information on Open Access is available for authors, including links to contacts and repositories which may be able to take eprints to fulfill funders' requirements and recommendations.

\subsection{European Union's view}

In the mid of the previous decade the European Commission funded a "Study on the economic and technical evolution of the scientific publication markets in Europe" in order to define the situation and formulate an appropriate strategy (Dewatripont 2006). One of the European Union's visions is the one stated by the Commissioner for Research, Innovation and Science, Máire Geoghegan-Quinn: "We need a European Research Area that is interconnected, structured, mobile and efficient; a unified research area that brings together people and ideas in a way that catalyses science and world-leading innovation. Open access can help make this vision become a reality".

In August 2008, the European Commission launched the 'Open Access Pilot in the Seventh Framework Programme (FP7), intended to provide researchers and other interested members of the public with improved online access to EU-funded research results.

The pilot aims to permit easy and free access to scientific information, in particular peer-reviewed scientific articles published in journals. Articles covered by the pilot will become accessible after an embargo period of 6 or 12 months, depending on the FP7 area.

The difference in embargo periods in Open Access (6 months or 12 months) is explained by the fact that research findings are considered 'new', and therefore have an economic value for different periods of time depending on the scientific discipline. The length of time after which the research results of rapidly changing disciplines (e.g. ICT) become out of date is relatively shorter than in the case of, for example, research results in the social sciences, which remain valid for a longer period. This model is in keeping with approaches developed by other funding bodies (the Commission's pilot is only one of many initiatives underway in Europe and beyond, such as WELCOME Trust).

\subsubsection{EU funded projects}

EU has several funded projects for implementing and/or supporting Open Access, such as:

ACUMEN (Academic Careers Understood through Measurement and Norms)

APARSEN (Metadata for preservation, curation and interoperability)

BELIEF II (To Promote the Efficient and Effective Communication of Results, Networking and Knowledge among EU e-Infrastructure Projects and their Users)

CESSDA (Council of European Social Science Data Archives) CLARIN (Common language resources and technology infrastructure)

COMMUNIA (Thematic Network on the Public Domain in the Digital Environment)

DARIAH (Digital Research Infrastructure for the Arts \& Humanities)

DRIVER II (Digital Repository Infrastructure Vision for European Research) 
e-SciDR (Towards a European Infrastructure for e-Science Digital Repositories)

EUROCANCERCOMS (Establishing an Efficient Network for Cancer Communication in Europe)

EUROVO-AIDA (Euro-VO Astronomical Infrastructure for Data Access)

LiquidPub (Liquid Publications: Scientific Publications meet the Web - Changing the Way Scientific Knowledge is Produced, Disseminated, Evaluated, and Consumed)

MEDOANET (Mediterranean Open Access Network)

NECOBELAC (Network of Collaboration between Europe and Latin American-Caribbean Countries)

OAPEN (Open Access Publishing in European Networks)

ODE (Opportunities for Data Exchange)

OpenAIRE (Open Access Infrastructure for Research in Europe)

OpenAIREplus ( $2^{\text {nd }}$ Generation of Open Access Infrastructure for Research in Europe)

PARSE.Insight (Permanent Access to the Records of Science in Europe)

PEER (Pilot Programme Investigating the Effect of the Deposit of Author Manuscripts on the Ecology of European Research and Publishing)

SISOB (An Observatorium for Science in Society based in Social Models)

SOAP (Study of Open Access Publishing by Key Stakeholders)

\subsection{University of Cyprus actions}

The Senate of the University of Cyprus, during its $23^{\text {rd }}$ meeting of 2008 which took place on the 5th of November of 2008, supported and accepted the Library Committee's proposal to sign the Berlin Declaration.

The Senate as the highest academic body of the University of Cyprus and responsible for the academic affairs of the University, decided to share the vision expressed in the Berlin Declaration on Open Access to Knowledge in the Sciences and Humanities.

The name of the University of Cyprus is included in the signatories list of the Berlin Declaration:

http://oa.mpg.de/lang/en-uk/berlin-prozess/signatoren/.

Furthermore the Library of the University of Cyprus is involved in two European Research projects (OpenAIRE and OpenAIREplus). Both projects aim the support of the implementation of Open Access in Europe.

\section{OPENAIRE}

\subsection{OpenAIRE overview}

OpenAIRE, a three-year project funded by the $7^{\text {th }}$ Framework Programme, aims to support the implementation of Open Access in Europe. OpenAIRE is establishing the infrastructure for researchers to support them in complying with the European Commission (EC) OA pilot and the European Research Council (ERC) Guidelines on Open Access. It provides the means to promote and realize the widespread adoption of the Open Access Policy, as set out by the ERC and the by the European Commission. It provides an extensive European Helpdesk System, based on a distributed network of national and regional liaison offices in 27 countries, to ensure localized help to

All the information for OpenAIRE was taken from the official OpenAIRE project website (www.openaire.eu). researchers within their own context. It has built an OpenAIRE portal and e-Infrastructure for the repository networks and is exploring scientific data management services together with 5 disciplinary communities. It provides a repository facility for researchers who do not have access to an institutional or discipline-specific repository. As Neelie Kroes, Vice-President of the European Commission for the Digital Agenda said: "The launch of OpenAIRE marks a very concrete step towards sharing the results of EU funded research to our mutual benefit. Scientific information has the power to transform our lives for the better - it is too valuable to be locked away. In addition, every EU citizen has the right to access and benefit from knowledge produced using public funds".

\subsubsection{OpenAIRE's objectives}

OpenAIRE's three main objectives are to:

- build support structures for researchers in depositing FP7 research publications through the establishment of the European Helpdesk and the outreach to all European member states through the operation and collaboration of 27 National Open Access Liaison Offices;

- establish and operate an electronic infrastructure for handling peer-reviewed articles as well as other important forms of publications (pre-prints or conference publications). This is achieved through a portal that is the gateway to all user-level services offered by the e-Infrastructure established, including access (search and browse) to scientific publications and other value-added functionality (post authoring tools, monitoring tools through analysis of document and usage statistics);

- work with several subject communities to explore the requirements, practices, incentives, workflows, data models, and technologies to deposit, access, and otherwise manipulate research datasets of various forms in combination with research publications.

Currently the European Commission has two policies on Open Access in practice. Both aim to ensure that research results funded by the EU citizen are made available to the population at large for free. In this way, Open Access is considered a way to improve the EU's return on research and development (R\&D) investment.

In December 2007, the ERC Scientific Council published its Guidelines for Open Access, as a follow up of the 2006 Statement on Open Access. In August 2008, the European Commission launched the Open Access Pilot in FP7 that will run until the end of the Framework Programme.

These initiatives require that the researcher provides open access to articles resulting from EC funded research, within a specified time period. Both initiatives have further special requirements; see ERC Guidelines for Open Access and Open Access Pilot in FP7.

ERC or from FP7 in one of the following Research Areas:

Energy, Environment (including Climate Change), Health, Information and Communication Technologies (Cognitive Systems, Interaction, Robotics), Research Infrastructures (einfrastructures), Science in society and Socio-economic sciences and the humanities.

Grant agreements in these areas signed after the beginning of the open access pilot will contain a special clause (39) requiring beneficiaries:

1. to deposit articles resulting from FP7 projects into an institutional or subject based repository;

2. to make their best efforts to ensure open access to these articles within six months (Energy, Environment, Health, Information and Communication Technologies, Research 
Infrastructures) or twelve months (Science in Society, Socioeconomic Sciences and Humanities).

Researchers should deposit final articles or manuscripts into the institutional repository of the research institution with which they are affiliated. If this is not possible, they should identify an appropriate subject based/thematic repository. The Commission provides a special repository for articles that can be stored neither in institutional nor in subject-based/thematic repositories.

Researchers should deposit final articles or manuscripts into:

- institutional repository of the research institution with which they are affiliated

- appropriate subject based/thematic repository.

- the Orphan Repository ${ }^{\S}$ for articles that can be stored neither in institutional nor in subject-based/thematic repositories. OpenAIRE's Orphan Repository is hosted by CERN and every researcher is free to deposit his/her publication in it.

\subsubsection{University of Cyprus Library role}

The University of Cyprus Library participates in the project as a National Open Access Desk (NOAD). The NOADs connect researchers, research institutions, and policy makers at a national level on the one end, and the OpenAIRE project services on the other. The focus of the National Open Access Desks activities is on support for compliance with the EC Open Access Pilot.

The National Open Access Desk can help researchers to find the appropriate repository in their native country, and can answer their questions concerning Open Access, the EC Open Access Pilot, copyright issues, any special national rules and regulations concerning Open Access, and so on. In principle each NOAD can provide the necessary information with respect to OpenAIRE, Open Access in general and the EC Open Access Pilot. They will redirect questions if necessary, especially when national issues, like copyright, are involved.

The University of Cyprus Library as the regional NOAD of Cyprus offers LEKYTHOS (academic - institutional repository of the University of Cyprus) to all the local researchers that would like to deposit their publications derived from projects funded under the scientific Areas above. Institutional Repositories are repositories that are maintained and curated by institutions - very often the library. Repositories collect, curate and make the research output of an institution available on the Internet. LEKYTHOS is fully compatible with the OpenAIRE platform and all the publications deposited in LEKYTHOS will become visible through the OpenAIRE platform also. Cyprus NOAD provides support to all the regional repository managers in Cyprus in order to help them in their effort to comply with the OpenAIRE platform.

\subsection{OpenAIREplus **}

OpenAIREplus (2nd Generation of Open Access Infrastructure for Research in Europe) was launched in Pisa in early December. The 30 month project, funded by the EC 7th Framework Programme, will work in tandem with OpenAIRE, extending the mission further to facilitate access to the entire

\footnotetext{
$\S$ The term "orphan" was replaced with the term "homeless" for this category of publications within the OpenAIRE consortium.

** All the information for OpenAIREplus was taken from the official OpenAIRE project website (www.openaire.eu)
}

Open Access scientific production of the European Research Area, providing cross-links from publications to data and funding schemes. This large-scale project brings together 41 pan-European partners, including three cross-disciplinary research communities.

The project will capitalise on the successful efforts of the OpenAIRE project which is rapidly moving from implementing the EU Open Access Pilot project into a service phase, enabling researchers to deposit their FP7 and European Research Area (ERA) funded research publications into Open Access repositories. The current publication repository networks will be expanded to attract data providers from domain specific scientific areas. "The participatory design of OpenAIREplus will seamlessly guide the researcher to Open Access research data. The experienced consortium will pave the way to support the research work of European scientists and open up the road to multi-disciplinary science" says Dr. Norbert Lossau, Scientific Coordinator of OpenAIREplus and Director of Göttingen State and University Library, Germany.

Creating a robust, participatory service for the cross-linking of peer-reviewed scientific publications and associated datasets is the principal goal of OpenAIREplus. As scholarly communication touches upon many disciplines, the project's horizontal outreach will facilitate collaboration across data infrastructures, providing information to scientists, nonscientists as well as to providers of value-added services. The project will establish an e-Infrastructure to harvest, enrich and store the metadata of Open Access scientific datasets. Innovative underlying technical structures will be deployed to support the management of and inter-linking between associated scientific data.

Access to and deposit of linked publications via the OpenAIRE portal will be supported by a Help Desk, and OpenAIRE's collaborative networking structure will be extended to promote the concept of open enhanced publications among user communities. Liaison offices in each of the project's 31 European countries work to support the needs of researchers in Europe. The project will also actively leverage its international connections to contribute to common standards, data issues and interoperability on a global level. The University of Cyprus Library participates in OpenAIREplus by representing the Cypriot NOAD in the same way as in OpenAIRE.

OpenAIREplus uses the publication base, the software tools \& services, the studies' results, and the extensive pan-European network of national representatives of the DRIVER and OpenAIRE infrastructure as a starting point. It enhances and expands the current functionality, interfaces, helpdesk services, and other activities to become operational in and consistent with the new environment envisioned.

Furthermore, it pushes on the following new main issues:

1. It expands the scope of the OpenAIRE technical and human infrastructure beyond the restricted realm of publications from project funded by the EC and having to abide to Special Clause.39, effectively offering an Open Access infrastructure to the entire scientific production of the European Research Area. Such an infrastructure does not exist at the moment but is crucial to foster growth and innovation.

2. In addition to dealing with publications, it also opens up to scientific datasets to a certain degree but in the same generic fashion. It harvests corresponding metadata from relevant repositories, aggregates them appropriately, and serves them to the other infrastructure services, e.g., search facilities and user functionality, similarly to publication metadata. It also offers a repository where researchers can deposit "homeless" datasets pertaining to their publications, if no other suitable repository 
exists. Central to this effort are services for cleaning and curation of the harvested metadata.

3. It offers services for several kinds of enrichment of the harvested metadata. Of key importance is the automatic, semiautomatic, or manual identification of links between publications and related datasets, projects, or other publications, and subsequent OpenAIREplus presentation of the resulting composite objects (rich enhanced publications) through appropriate visual representations. The starting point for this is the preliminary enhanced publication model (between publications only) prototyped in DRIVER-II. Equally significant are the extraction and derivation of other critical information, such as subject identification, bibliographic and usage trends detection, and other statistics calculations. Central to this effort are services for mining the harvested metadata and possibly other resources at various levels and for visualization of restricted data forms.

4. It makes its scientific information resources available to higher-level applications and providers of value-added services as well as to new communities and sections of society, e.g., scientists from disciplines other than those producing the resources, industry, or even the general public. It offers multiple interaction pathways to its content, each one appropriate for the characteristics of a different consuming application type or the interests and backgrounds of a different user type. Furthermore, it develops functionality enabling active participation of scientists and its general user constituency in the formation, enrichment, and use of the infrastructure content. Central to this effort are services related to adaptation and customization, community formation and interaction, and user interfaces.

5. It establishes connections with other infrastructures and several diverse forms of research content systems (e.g., D4Science, UKPubMed, DANS, other repositories, data archives, CRISs, DataCite) to enable harvesting of their resources. Given the present heterogeneity of such systems in terms of software platforms, service interfaces, and content formats, OpenAIREplus puts particular emphasis on establishing interoperability among them and its infrastructure. Central to this effort are the use of standards and services for harmonizing the differences among participating systems.

6. It studies several thorny issues related to the legal status of publications and datasets and promotes particular open-access licensing models for specific contents, so that the desired open access to all resources by several communities can be realized. Central to this effort are issues related to provenance, intellectual property rights, and conditions of reuse.

7. Likewise, it studies and analyses several possible models and options for a possible longterm scenario and an according business model that aims at the sustainability of the infrastructure.

\section{OPEN ACCESS AND CULTURAL HERITAGE}

\subsection{Europeana : the portal to cultural heritage}

Europeana is an internet portal that acts as an interface to millions of books, paintings, films, museum objects and archival records that have been digitised throughout Europe.

Among professionals in the heritage sector, Europeana is also a platform for knowledge exchange that promotes collaboration between librarians, curators, archivists and the creative industries.

Europeana gives access to different types of content from different types of heritage institutions, such as libraries, museums, archives etc. The digital objects can be found and accessed by users online via the networks of the cultural institution that owns it and hosts it. Europeana collects contextual information - or metadata - about the items, including a small picture. Users search this contextual information. Once the users find what they are looking for, if they want to access the full content of the item, they can click through to the original site that holds the content.

Cyprus is involved in this project by contributing digital objects of the local cultural heritage. A local aggregator which concentrates the digital objects is created and heritage institutions in cooperation with the local Ministry of Education and Culture, are providing important historical cultural heritage objects to the public through Europeana.

In order for the content to be provided via the portal, the institutions have to sign the "Data exchange agreement ${ }^{[1]}$,, which among others, assures that the objects can be freely available and the data provider has made best efforts to provide Europeana with correct Metadata on the Intellectual Property Rights to the Content, including the identification of Content that is Public Domain as being Public Domain (Article 2, paragraph 3.).

The University of Cyprus library has signed the "Data exchange agreement" in April 2012, and has already provided around 4000 cultural heritage objects.

The content of Europeana falls in the grey zone of the definition of an object as a cultural heritage document and a pure raw research data. For example, providing an audio object with an interview of a veteran warrior telling his story and point of view, might have historical importance but it might also have importance for the research of a political analyst or an interest for a linguistic researcher.

Open access to any kind of cultural heritage documents, is giving the chance to users/researchers to have access in important items, where they can find valuable sources for their research.

In addition a country can benefit in several socioeconomic ways by showing the culture and the civilization of the country, the origins the habits of people living there etc

Concluding is important to mention that Open access for a small country like Cyprus has a bigger marginal value than other countries of the E.U. Taking part in projects like Europeana or any other projects supporting Open access can only benefit Cyprus.

\subsection{Public Sector Information (PSI) and Orphan works directives}

The Council and the European Parliament have adopted The Directive on the re-use of public sector information which deals with the way public sector bodies should enhance re-use of their information resources (the Directive 2003/98/EC of 17 November 2003 was published in the Official Journal (L345/90) on 31 December 2003).

The Directive is built around two key pillars of the internal market: transparency and fair competition. It sets minimum rules for the re-use of PSI throughout the European Union. In its recitals it encourages Member States to go beyond these

[1] The Data exchange agreement is available online through the address:

http://pro.europeana.eu/documents/10602/560317/Data+Exchange+ Agreement+-+Final+-+clean.pdf 
minimum rules and to adopt open data policies, allowing a broad use of documents held by public sector bodies.

In parallel there is the Orphan works directive. The Commission has adopted a Proposal for a Directive on certain permitted uses of orphan works with a view to establishing common rules on the digitisation and online display of socalled orphan works. Orphan works are works like books, newspaper and magazine articles, and films that are still protected by copyright but whose authors are not known or cannot be located or contacted to obtain copyright permissions. Orphan works are part of the collections held by European libraries that might remain untouched if no common rules are developed to make their digitisation and online display legally possible. Common rules on how to deal with such works are therefore necessary in order to proceed with large-scale digitisation projects, such as the Commission's Europeana portal.

Both directives are working as reinforcements made by the European Commission for introducing Open Access in EU member states .

\section{CONCLUSION}

According to the OpenAIRE project (www.openaire.eu) there are significant economic, social and educational benefits to making research outputs available without financial, legal and technical barriers to access. Open Access to conclude incorporates national research into an interoperable network of global knowledge, increases national research impact, provides new research partnerships, and removes professional isolation.

Society as a whole benefits because research is more efficient and more effective, delivering better and faster outcomes for all. Open Access strengthens economies through developing a strong and independent national science base. There is growing evidence that countries also benefit because Open Access increases the impact of the research in which they invest public money and therefore there is a better return on investment (Houghton, 2009). This new approach is leading today's publishing attitude and the University of Cyprus Library will continue to support and comply with all the EU recommendations regarding the Open Access publishing.

\section{References from Journals:}

Dewatripont, M.(et al.), 2006. Study on the economic and technical evolution of the scientific publication markets in Europe, European Commission, Brussels.

http://ec.europa.eu/research/science-society/pdf/scientificpublication-study_en.pdf

Houghton, J., 2009. Open Access - What are the economic benefits? A comparison of the United Kingdom, Netherlands and Denmark. Centre for Strategic Economic Studies, Victoria University, Melbourne:

http://www.knowledge-exchange.info/Default.aspx?ID=316

Jeffery, G. K. 2006, Open Access: An Introduction. ERCIM News No. 64, pp.16-17.

Kyrillidou, M. (et al.), 2004. "ARL Statistics 2002-03. A Compilation of statistics from the one hundred and twenty-three members of the Association of Research Libraries." ARL Statistics.

\section{References from websites:}

Geoghegan-Quinn, M., 2011. Speech on Launch of the ERA (Framework) Consultation

http://europa.eu/rapid/pressReleasesAction.do?reference=SPEE CH/11/571\&type=HTML (accessed on 29 May 2012)

European Commission: Europeana Libraries: Europeana Libraries: Aggregating digital content from Europe's libraries http://ec.europa.eu/information_society/apps/projects/factsheet/ index.cfm?project_ref=270933 (accessed on 06 August 2012)

European Commission: Legislative Actions - PSI Directive http://ec.europa.eu/information_society/policy/psi/actions_eu/p olicy_actions/index_en.htm (accessed on 06 August 2012)

European Commission: National open access and preservation policies in Europe Analysis of a questionnaire to the European Research Area Committee.

http://ec.europa.eu/research/science-

society/document_library/pdf_06/open-access-report-

2011_en.pdf (accessed on 30 May 2012)

European Commission: Research and innovation - science in society.

http://ec.europa.eu/research/science-

society/index.cfm?fuseaction=public.topic\&id=1294\&lang=1 http://ec.europa.eu/research/science-

society/index.cfm?fuseaction=public.topic\&id=1300\&lang $=1$ (accessed on 30 May 2012)

Europeana foundation: Data exchange agreement http://pro.europeana.eu/documents/10602/560317/Data+Exchange+Agr eement+-+Final+-+clean.pdf (accessed on 06 August 2012)

Europeana.eu

http://www.europeana.eu/portal/ (accessed on 06 August 2012)

Harvard University, Faculty Advisory Council Memorandum on Journal Pricing "Major Periodical Subscriptions Cannot Be Sustained"

http://isites.harvard.edu/icb/icb.do?keyword=k77982\&tabgroup id=icb.tabgroup 143448 (accessed 28 May 2012)

Kroes, N., 2010. EC Press release (Brussels, 2 December 2010)

http://www.openaire.eu/en/component/content/article/76-

highlights/214-eu-openaire-launch-pr (accessed on 01/06/2012)

Project OpenAIRE

www.openaire.eu (accessed on 01/06/2012)

\section{Project RoMEO}

http://www.lboro.ac.uk/departments/ls/disresearch/romeo/ (accessed on 29 May 2012)

Sherpa Juliet: Research funders' open access policies http://www.sherpa.ac.uk/juliet/index.php (accessed on 29 May 2012)

Suber, P., "Open Access Overview: Focusing on open access to peer-reviewed research articles and their preprints" http://www.earlham.edu/ peters/fos/overview.htm (accessed 28 May 2012) 